\section{Futebol e mulheres}

\section{Daniel Kfouri}

A seção Poética apresenta a série composta por nove imagens, de Daniel Kfouri, produzidas para o Coletivo

Guerreiras Project, em 2014. As fotografias fizeram parte da exposição "Futebol e mulheres no país da Copa", realizada na Usina do Gasômetro, em Porto Alegre, ao

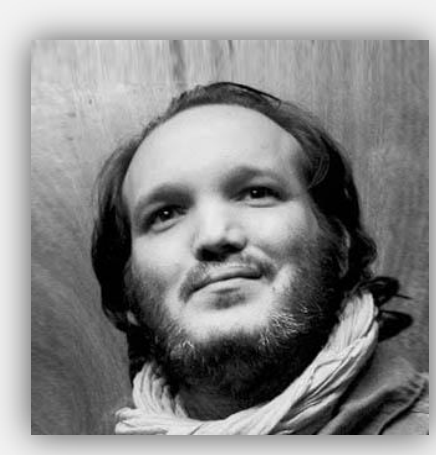
longo da Copa do Mundo FIFA 2014.

0 artista visual é filho de Juca Kfouri, um dos maiores jornalistas esportivos do Brasil e pensador da cultura sóciofutebolística, o que certamente influenciou a singular maneira de Daniel olhar o mundo, pois publicou algumas séries sobre o esporte com um foco sensível às performatividades marginalizadas: Mais que uma medalha, imagens das Paralimpíadas Rio 2016, Campo dos sonhos, que recai sobre o polo aquático, Mulheres de areia, mostrando o futebol de areia praticado por mulheres, e Várzea, sobre o futebol na periferia. Além das séries que homenageiam Neymar e o Corinthians, Magrelo 2009-17 e Não para, respectivamente.

Daniel Kfouri (1975) nasceu em São Paulo. Começou a fotografar em 2001 após trabalhar seis anos como designer gráfico. Já colaborou para revistas da Editora Abril, Folha de São Paulo, The New York Times e agências de notícias. Cobriu a Copa do Mundo 2014 para a revista Veja. Faz trabalhos autorais no intuito de desenvolver sua linguagem fotográfica. Já foi premiado em dois concursos internacionais, o World Press Photo, em 2010, e o Picture of the Year Latin America, em 2011. Publicou Hi-fi (2018), fotolivro, vencedor do Prêmio Foto em Pauta (2017), fruto de duas viagens a Cuba.

Site: http://danielkfouri.photoshelter.com. Fotografia do artista: Projeto Foto em Pauta, Minas Gerais. Conf.: http://fotoempauta.com.br/daniel-kfouri/. 


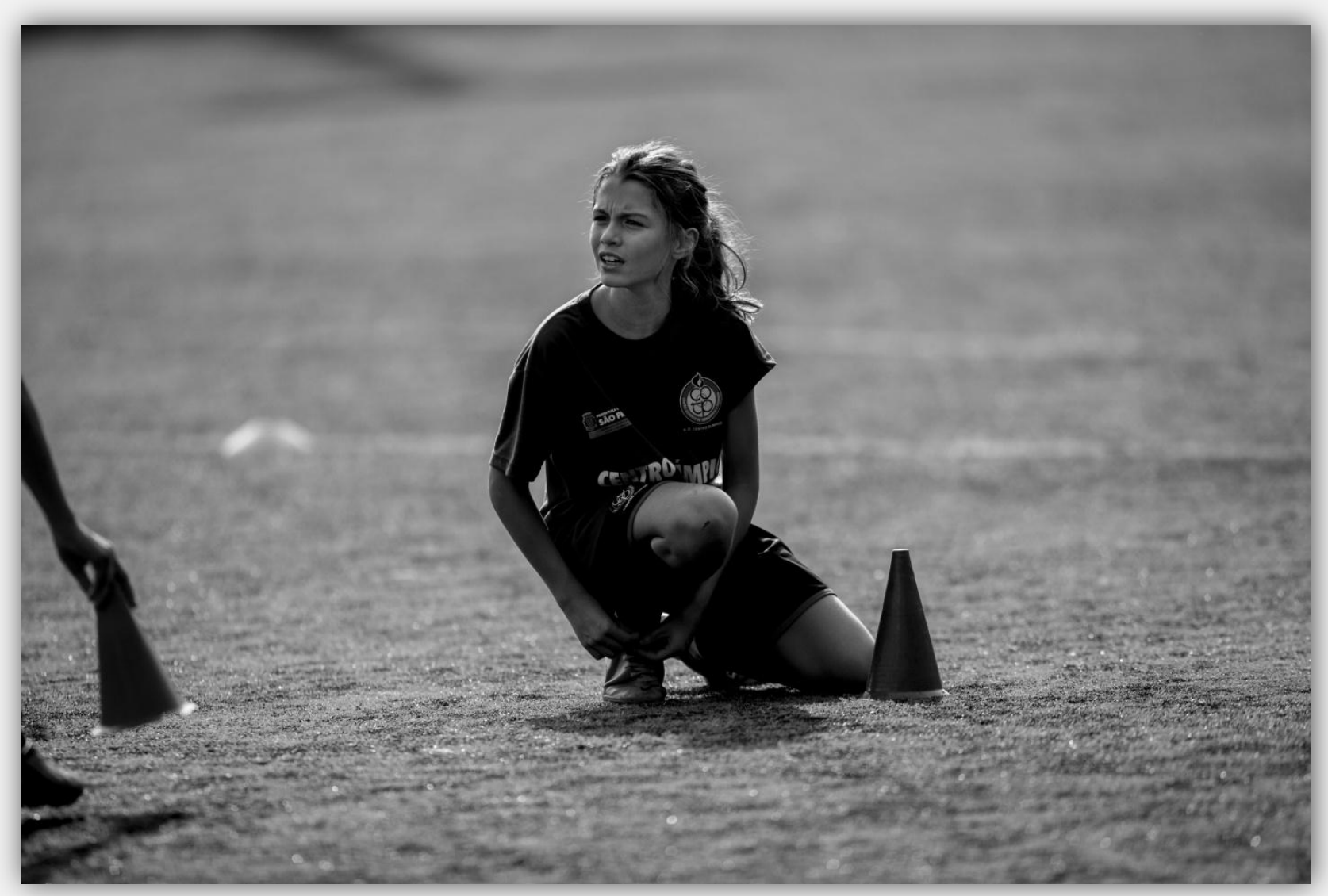

Young Seated 


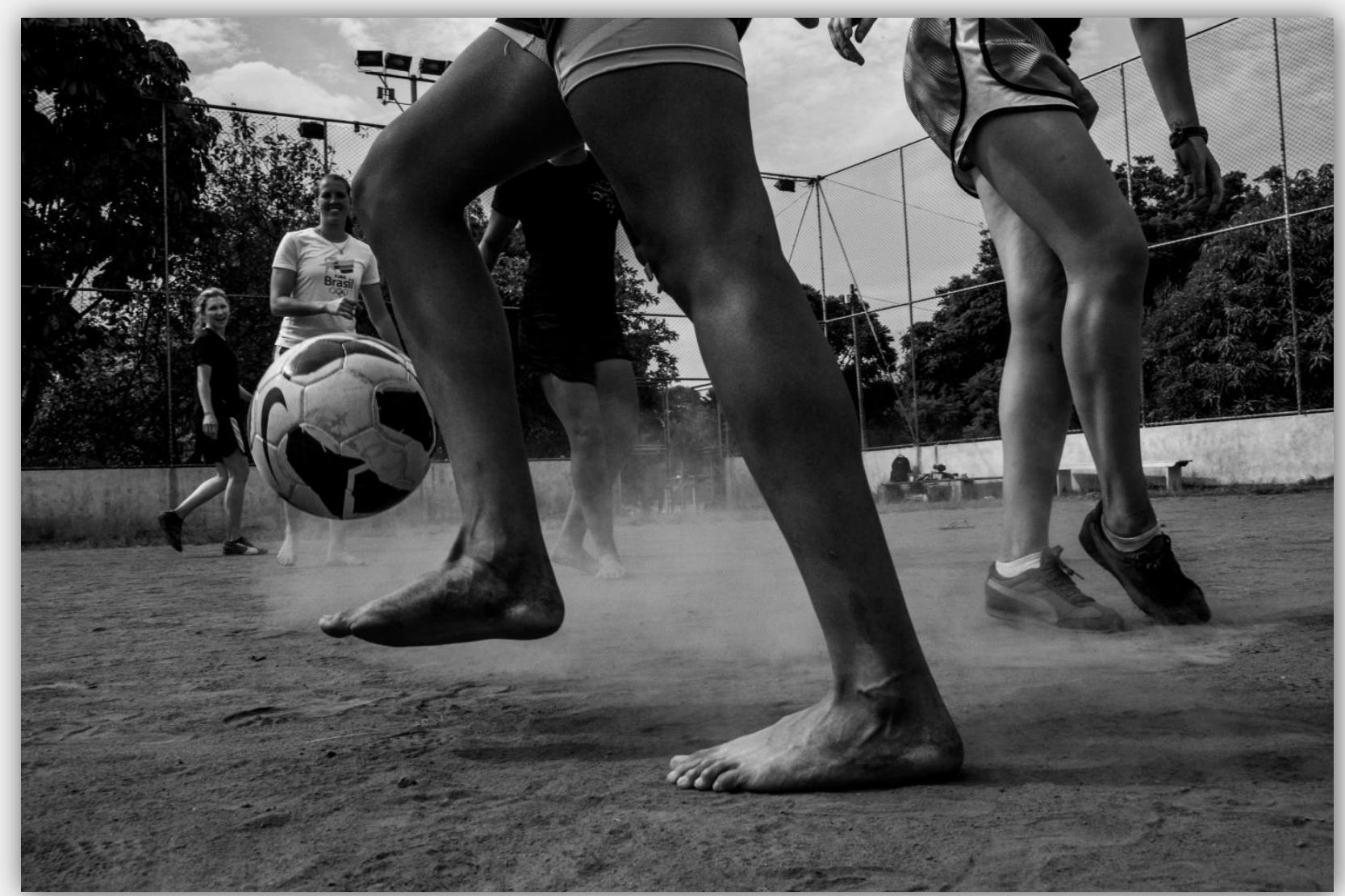

Juggle 


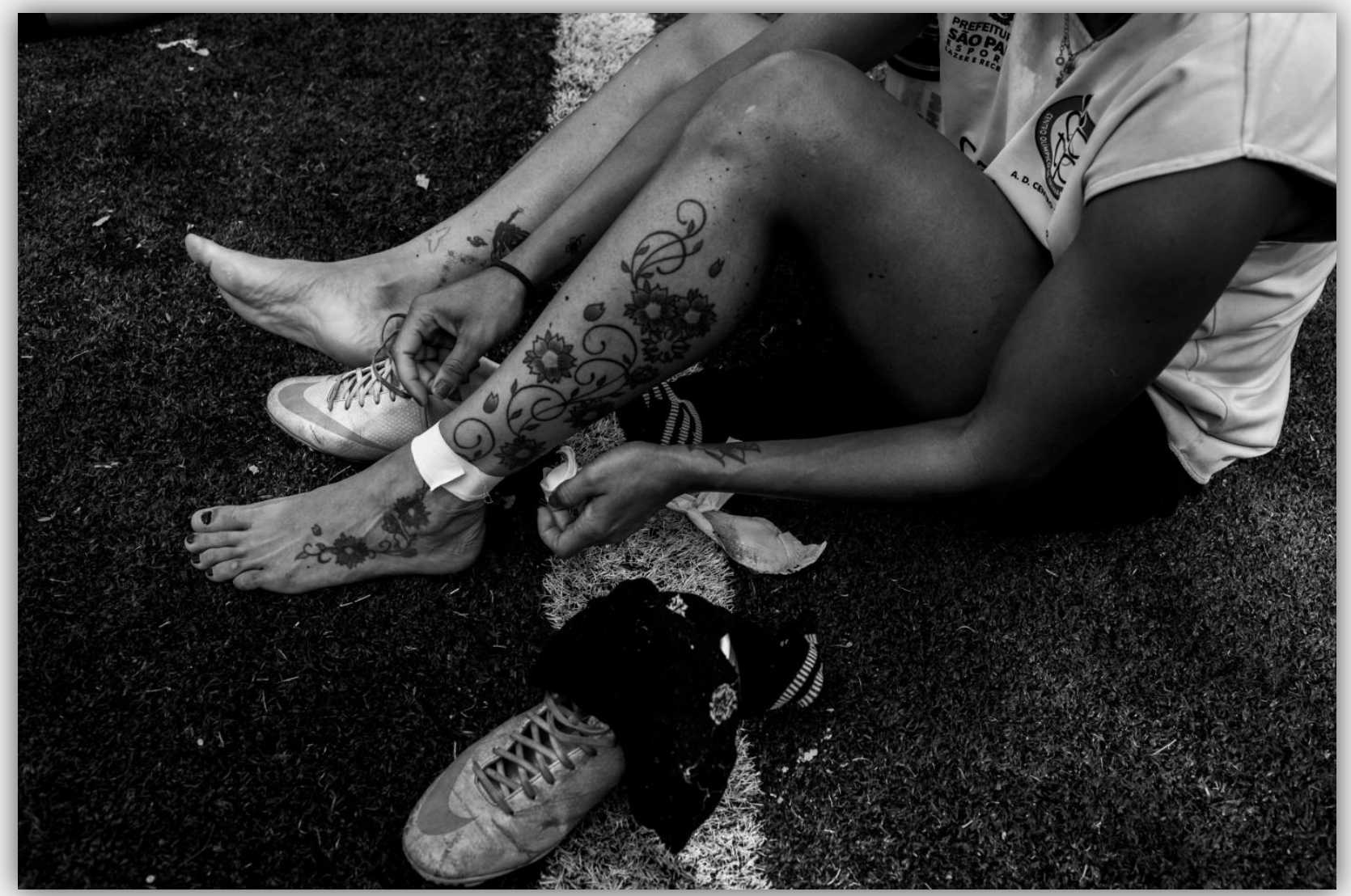

Flower Tatoo 


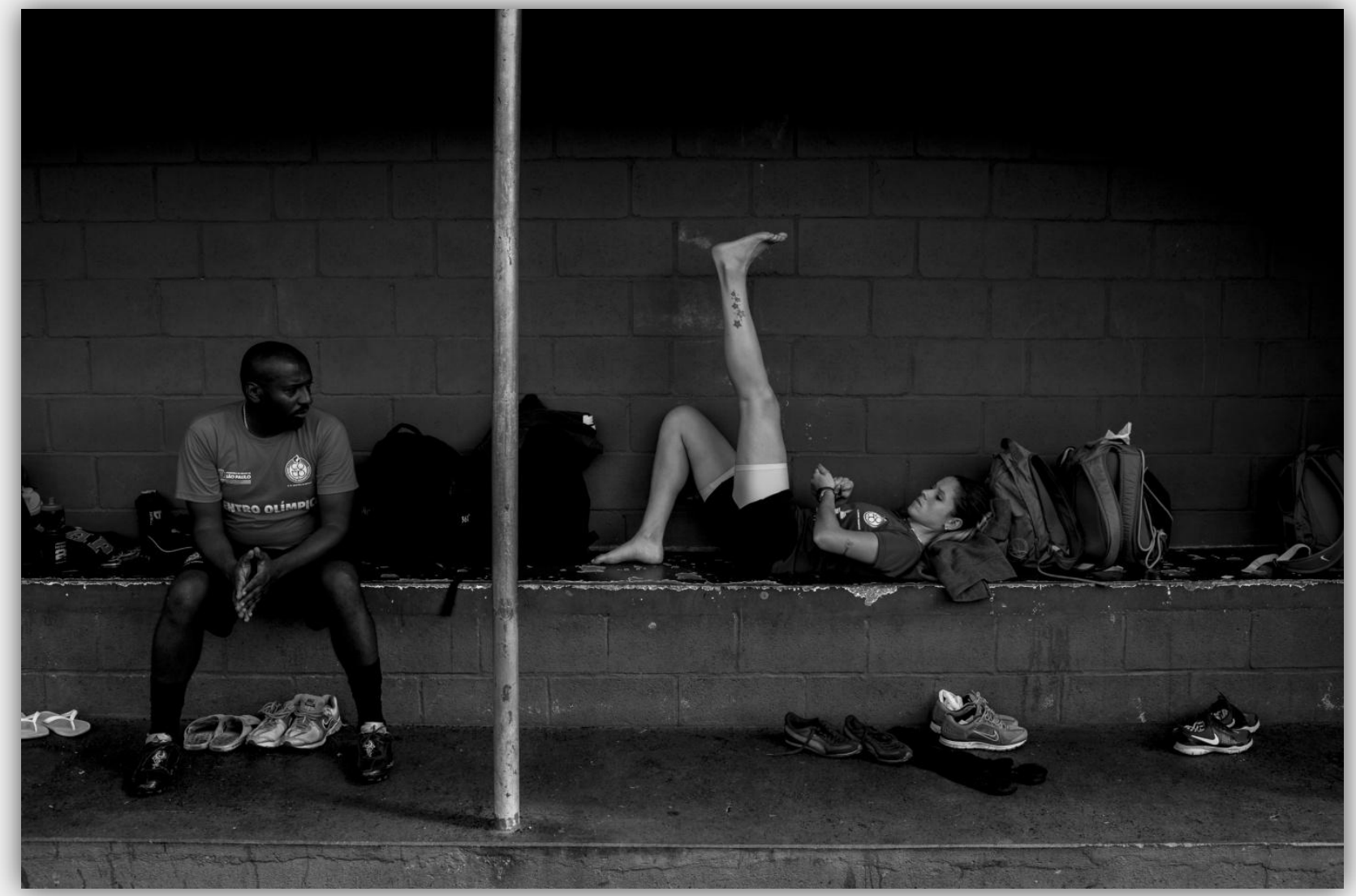

Érika 


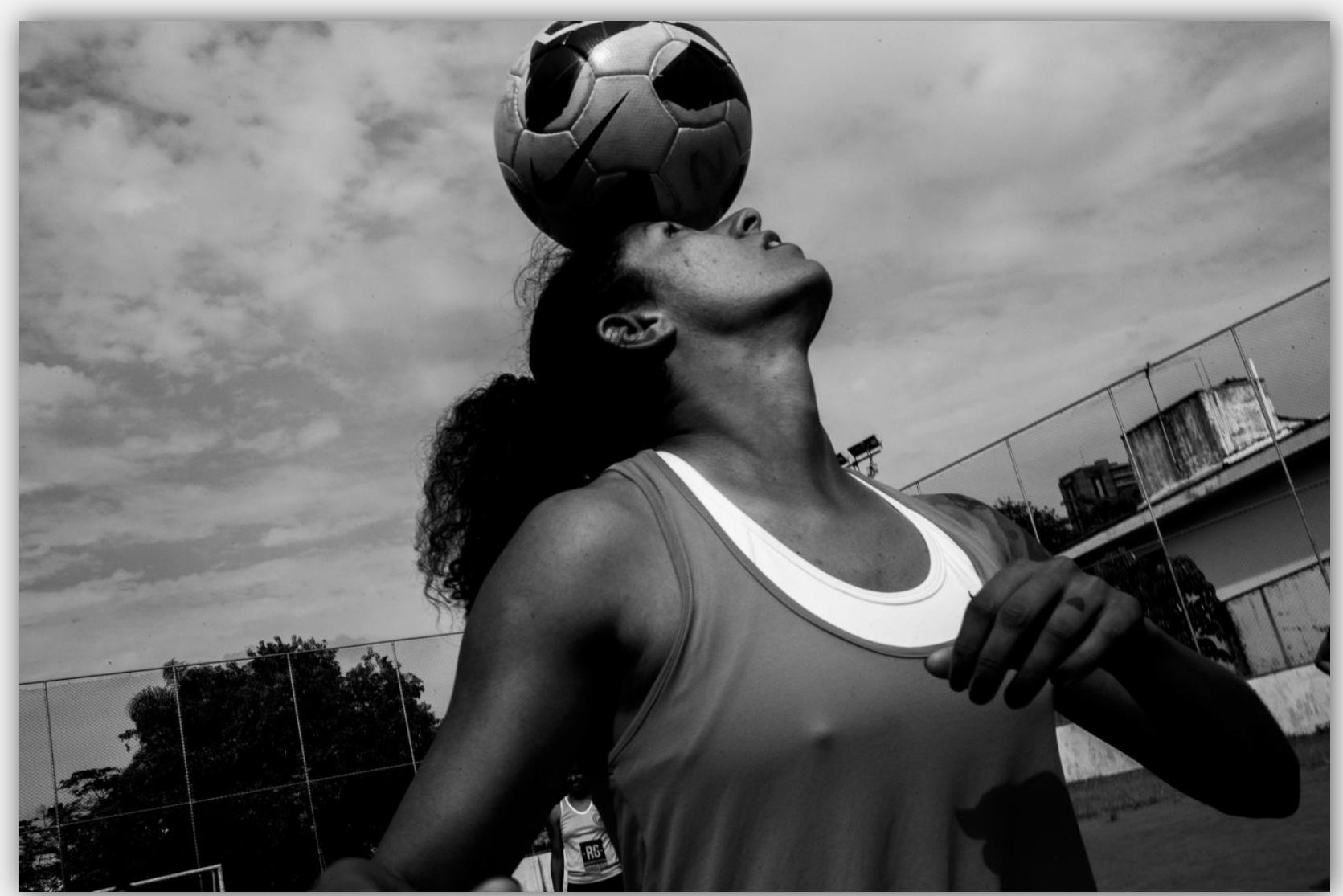

Cris Head 


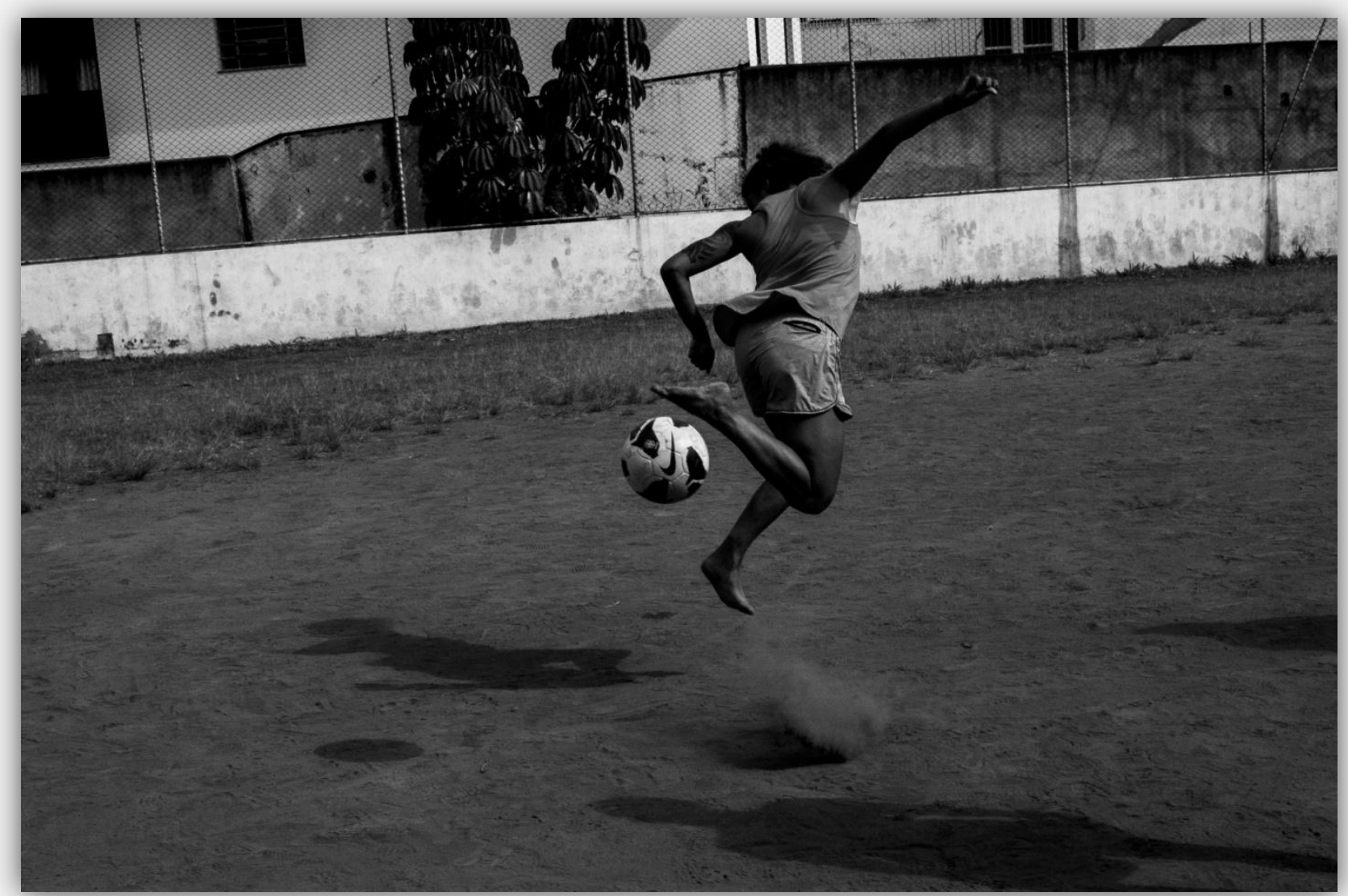

Cris Rainbow 


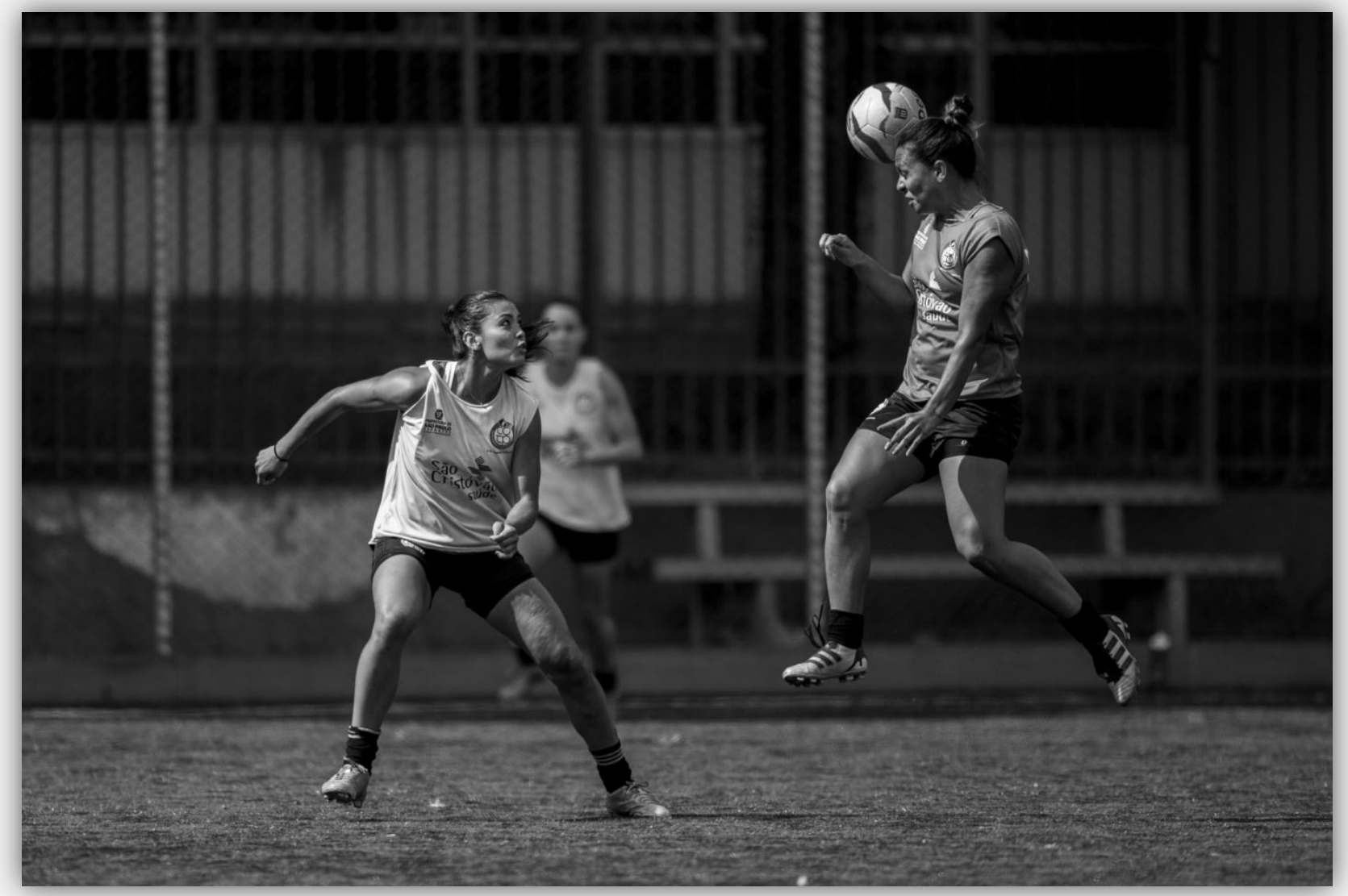

Luize Header

Capa da revista FuLiA / UFMG, v. 4, n. 1, 2019. 


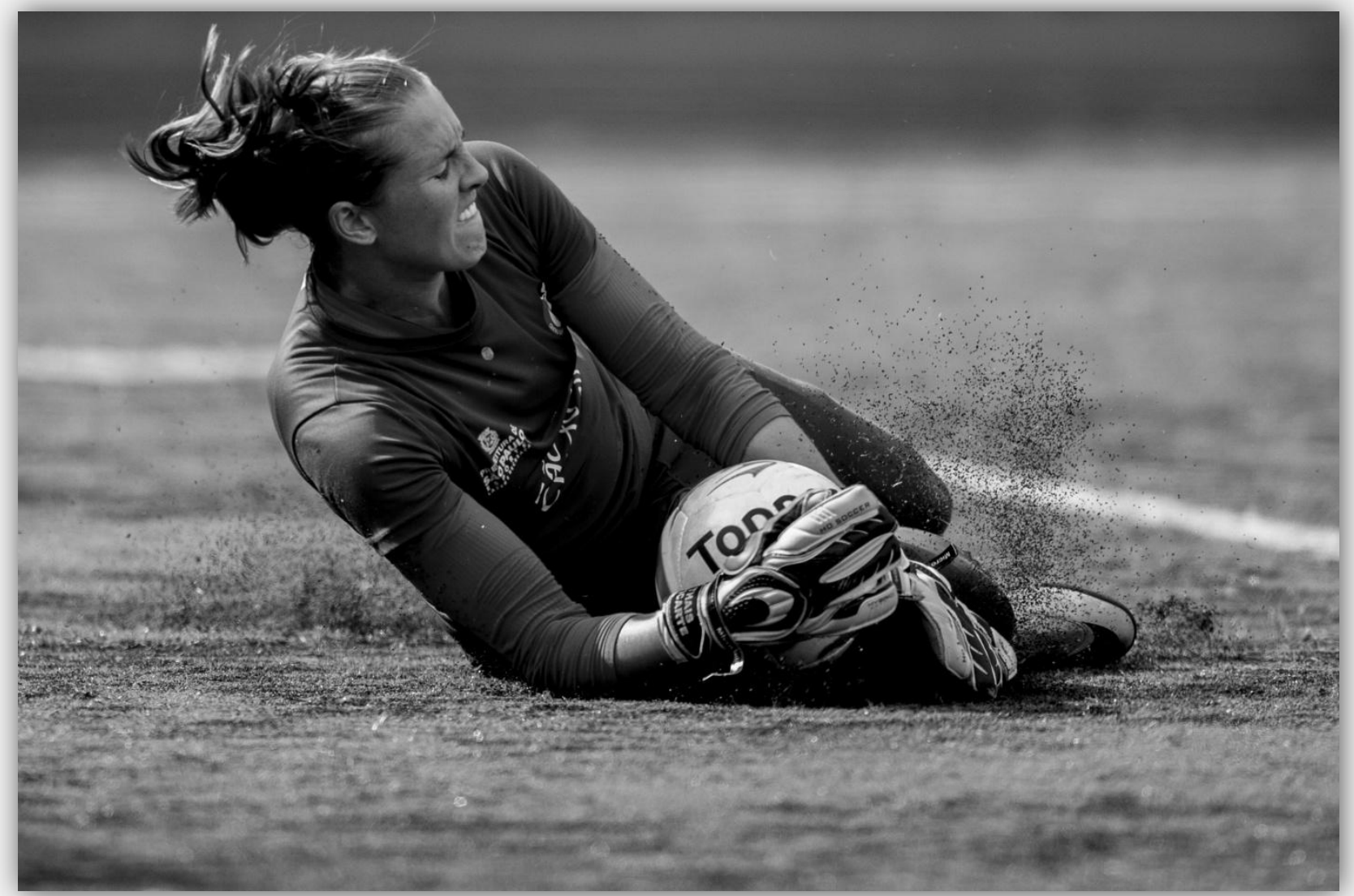

Thais Dots 


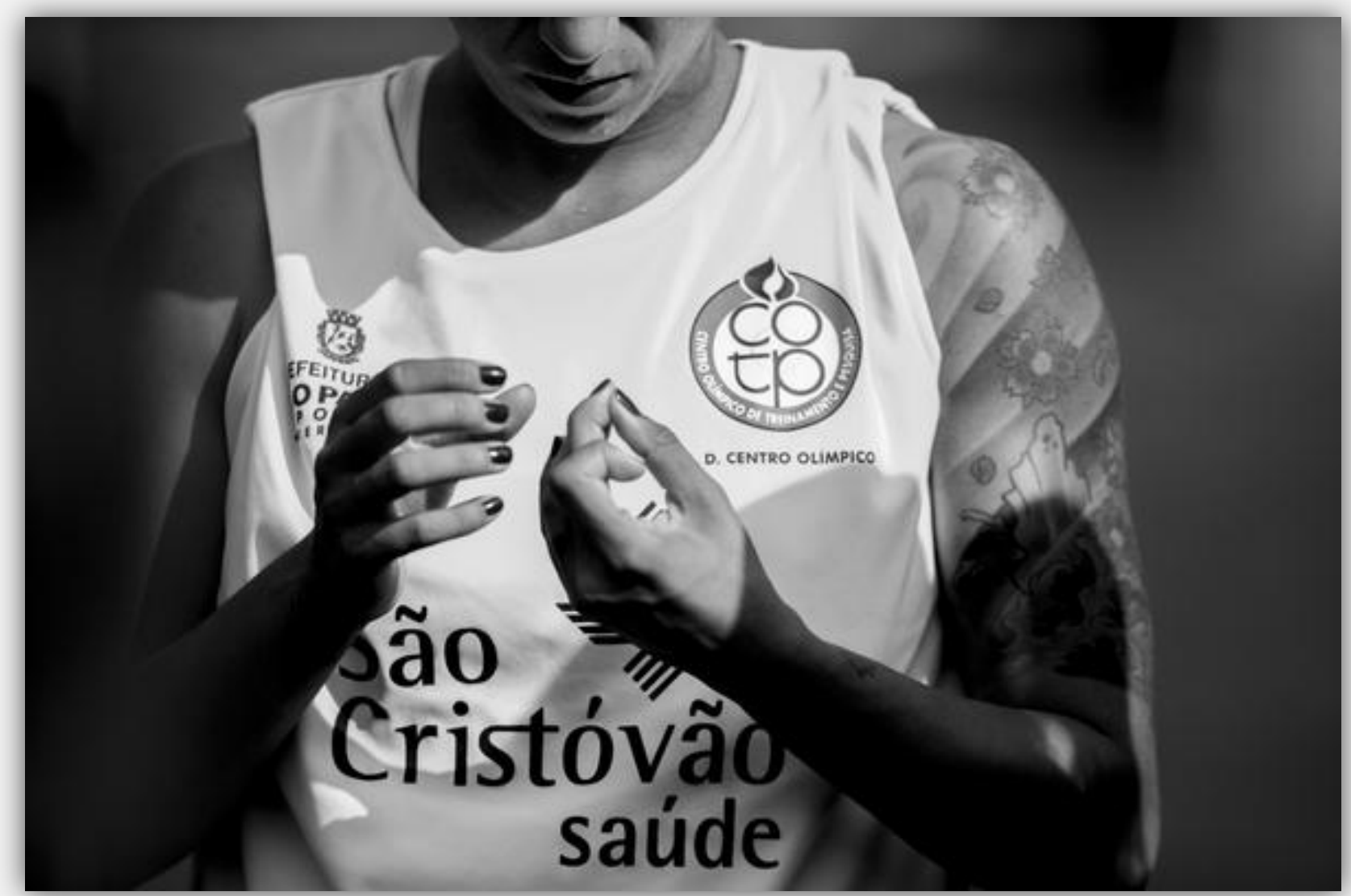

Nails 